\title{
Synthesis and structural and magnetic characterisation of cobalt(II)-sodium phosphonate cage compounds $\dagger$
}

\author{
Stuart Langley, ${ }^{a}$ Madeleine Helliwell, ${ }^{a}$ Roberta Sessoli, ${ }^{b}$ Simon J. Teat ${ }^{c}$ and Richard E. P. Winpenny ${ }^{* a}$ \\ Received 10th November 2008, Accepted 12th February 2009 \\ First published as an Advance Article on the web 6th March 2009 \\ DOI: $10.1039 / b 819976 k$
}

\begin{abstract}
The reaction of cobalt salts with phosphonic acids in the presence of 6-chloro-2-hydroxypyridine as a co-ligand, using sodium methoxide as a base, leads to a series of new polymetallic cobalt cages. Variation of the phosphonate present and the cobalt salt leads to $\left\{\mathrm{Co}_{6} \mathrm{Na}_{8}\right\},\left\{\mathrm{Co}_{12}\right\},\left\{\mathrm{Co}_{13} \mathrm{Na}_{6}\right\}$, $\left\{\mathrm{Co}_{14} \mathrm{Na}_{4}\right\}$ and $\left\{\mathrm{Co}_{15} \mathrm{Na}\right\}$ cages, all of which have been characterized by X-ray crystallography. Using lithium methoxide produces a sixth cage with a $\left\{\mathrm{Co}_{6} \mathrm{Li}_{9}\right\}$ core. The structures are, in general, extremely irregular with no structural motifs common to the six cages. Magnetic studies of these cages show a general decline in the product $\chi_{\mathrm{m}} T$ with $T$, but for $\left\{\mathrm{Co}_{13} \mathrm{Na}_{6}\right\},\left\{\mathrm{Co}_{15} \mathrm{Na}\right\}$ and $\left\{\mathrm{Co}_{12}\right\}$ there are maxima at low temperature, which suggest non-diamagnetic ground states. Investigation of the dynamic behaviour of the magnetisation of these complexes shows that the $\left\{\mathrm{Co}_{13} \mathrm{Na}_{6}\right\}$, and possibly the $\left\{\mathrm{Co}_{12}\right\}$ cage, appear to display slow relaxation of magnetisation.
\end{abstract}

\section{Introduction}

In a previous paper $^{1}$ we have shown that polymetallic cobalt complexes can be made using phosphonates as ligands. Variation of the phosphonate present and the cobalt salt leads to $\left\{\mathrm{Co}_{6}\right\}$, $\left\{\mathrm{Co}_{8}\right\},\left\{\mathrm{Co}_{10}\right\},\left\{\mathrm{Co}_{11}\right\},\left\{\mathrm{Co}_{12}\right\},\left\{\mathrm{Co}_{13}\right\}$ and $\left\{\mathrm{Co}_{20}\right\}$ cages, all of which have been characterized by $\mathrm{X}$-ray crystallography. This work was inspired partly by synthetic work on phosphonates by the groups of Zubieta ${ }^{2}$ and Chandrasekhar, ${ }^{3}$ and in part by the continuing interest in the magnetic properties of polymetallic compounds. ${ }^{4}$ In particular we hoped that the unquenched spinorbit coupling of $\mathrm{Co}$ (II) might lead to new examples of slow relaxation of magnetisation. Previous work, ${ }^{1,5-8}$ has shown that $\mathrm{Co}$ (II) cages can show behaviour reminiscent of single molecule magnets. There have also been recent papers seeking to understand the magnetic coupling within polymetallic cobalt(II) compounds, e.g. by Cotton, Tsukerblat and co-workers, ${ }^{9 a}$ and by Chibotaru et $a l^{9 \mathrm{~b}, \mathrm{c}}$ This paper extends our previous work $^{1}$ where we had used 6-chloro-2-pyridonate (chp) as a co-ligand with phosphonate. In the previous work triethylamine was used as the base to deprotonate the phosphonic acid and 6-chloro-2-pyridinol. Here we have used sodium methoxide, and on one occasion lithium methoxide, as the base. As the alkali metal ions are retained in the product, this leads to new structural types. Here we report

${ }^{a}$ School of Chemistry, The University of Manchester, Oxford Road, Manchester, UK M13 9PL. E-mail: richard.winpenny@manchester.ac.uk; Fax: +44-161-275-4616

${ }^{b}$ Laboratorio di Magnetismo Molecolare, Dipartimento di Chimica, Università degli Studi di Firenze, Polo Scientifico Universitario, Via Lastruccia n. 3, 50019, Sesto Fiorentino, Italy

'Advanced Light Source, Lawrence Berkeley National Lab, 1 Cyclotron Road, mail stop 2-400 Berkeley, CA, 94720, USA

$\dagger$ Electronic supplementary information (ESI) available: Additional magnetic data. CCDC reference numbers 210156, 210159,708576 and 708577. For ESI and crystallographic data in CIF or other electronic format see DOI: $10.1039 / \mathrm{b} 819976 \mathrm{k}$ the synthesis, X-ray analysis and magnetic studies of six new cobalt(II) phosphonate cage complexes. The work is an extension of an approach pioneered by Chandrasekhar, where copper phosphonate cages were solubilised by addition of pyrazole, ${ }^{3}$ replacing pyrazole with 6-chloro-2-pyridonate (chp), which is an excellent ligand for making polymetallic cobalt complexes. ${ }^{10}$

\section{Experimental}

\section{Preparation of compounds}

All reagents, metal salts and ligands were used as obtained from Aldrich. Analytical data were obtained by the microanalytical service of the University of Manchester.

Synthesis of $\left[\mathrm{Co}_{14} \mathrm{Na}_{4}(\mathrm{chp})_{20}\left(\mathrm{O}_{3} \mathrm{PPh}\right)_{6}(\mathrm{Hchp})_{2}\left(\mathrm{H}_{2} \mathrm{O}\right)_{8}\right]$ 1. Cobalt(II) nitrate hexahydrate $(0.58 \mathrm{~g}, 2 \mathrm{mmol})$ was dissolved in methanol $(25 \mathrm{~mL})$. To this was added Hchp (0.52 g, $4 \mathrm{mmol})$, $\mathrm{PhPO}_{3} \mathrm{H}_{2}(0.052 \mathrm{~g}, 0.33 \mathrm{mmol})$ and $0.5 \mathrm{M} \mathrm{NaOMe}$ solution in methanol (9.32 mL, $4.66 \mathrm{mmol})$. A deep purple solution resulted which was stirred for $6 \mathrm{~h}$. The solution was then filtered and solvent removed to give a purple solid. Crystallization by extraction with $\mathrm{CH}_{2} \mathrm{Cl}_{2}$ followed by layering with hexanes gave deep purple crystals. Yield $0.21 \mathrm{~g}, 29.1 \%$. Elemental analysis (\%) calculated for $\mathrm{Co}_{14} \mathrm{C}_{146} \mathrm{H}_{110} \mathrm{~N}_{22} \mathrm{O}_{48} \mathrm{P}_{6} \mathrm{Cl}_{22} \mathrm{Na}_{4}$ : C 36.36, $\mathrm{H}$ 2.36, $\mathrm{N}$ 6.37: found $\mathrm{C}$ 36.94, H 2.49, N 6.13 .

Synthesis of $\left[\mathrm{Co}_{6} \mathrm{Na}_{\mathbf{8}}(\mathrm{chp})_{12}\left(\mathrm{O}_{3} \mathrm{PPh}\right)_{4}(\mathrm{MeCN})_{4}\right] 2$. Preparation as 1 except that $\mathrm{CoCl}_{2} \cdot 6 \mathrm{H}_{2} \mathrm{O}(0.47 \mathrm{~g}, 2 \mathrm{mmol})$ was used in place of $\mathrm{Co}\left(\mathrm{NO}_{3}\right)_{2} \cdot 6 \mathrm{H}_{2} \mathrm{O}$ and crystallization was by extraction into $\mathrm{MeCN}$ followed by slow evaporation. Yield: $0.073 \mathrm{~g}, 7.2 \%$. Elemental analysis (\%) calculated for $\mathrm{Co}_{6} \mathrm{C}_{92} \mathrm{H}_{84} \mathrm{~N}_{16} \mathrm{O}_{26} \mathrm{P}_{4} \mathrm{Cl}_{12} \mathrm{Na}_{8}$ (2. $2 \mathrm{H}_{2} \mathrm{O}$ ): C 37.90, H 2.90, N 7.69: found C 37.71, H 2.34, N 7.40.

Synthesis of $\left[\mathrm{Co}_{13} \mathrm{Na}_{6}(\mathrm{chp})_{20}\left(\mathrm{O}_{3} \mathrm{PPh}\right)_{5}(\mathrm{OH})_{2}(\mathrm{MeCN})\left(\mathrm{H}_{2} \mathrm{O}\right)(\mathrm{Me}-\right.$ OH)] 3. Preparation as 1 except that $\mathrm{PhCH}_{2} \mathrm{PO}_{3} \mathrm{H}_{2}(0.58 \mathrm{~g}$, $0.33 \mathrm{mmol}$ ) was used in place of $\mathrm{PhPO}_{3} \mathrm{H}_{2}$ and crystallization 
was by extraction into $\mathrm{MeCN}$ followed by slow evaporation. Yield: $0.093 \mathrm{~g}, 13 \%$. Elemental analysis (\%) calculated for $\mathrm{Co}_{13} \mathrm{C}_{133} \mathrm{H}_{103} \mathrm{~N}_{21} \mathrm{O}_{41} \mathrm{P}_{5} \mathrm{Cl}_{19} \mathrm{Na}_{6}$ : C 36.43, $\mathrm{H}$ 2.37, $\mathrm{N}$ 6.71: found $\mathrm{C}$ 36.42, H 2.35, N 6.02.

Synthesis of $\left[\mathrm{Co}_{15} \mathrm{Na}(\mathrm{chp})_{22}(\mathrm{Hchp})_{2}\left(\mathrm{O}_{3} \mathrm{PEt}\right)_{3}(\mathrm{OH})_{3}\left(\mathrm{H}_{2} \mathrm{O}\right)_{3}(\mathrm{Me}-\right.$ $\mathrm{CN})_{3}$ ] 4. Preparation as 1 except $\mathrm{Co}\left(\mathrm{BF}_{4}\right)_{2} \cdot 6 \mathrm{H}_{2} \mathrm{O}(0.68 \mathrm{~g}, 2 \mathrm{mmol})$ was used in place of $\mathrm{Co}\left(\mathrm{NO}_{3}\right)_{2} \cdot 6 \mathrm{H}_{2} \mathrm{O}$ and $\mathrm{EtPO}_{3} \mathrm{H}_{2}(0.37 \mathrm{~g}$, $0.33 \mathrm{mmol}$ ) was used in place of $\mathrm{PhPO}_{3} \mathrm{H}_{2}$. Crystallization was by extraction into $\mathrm{MeCN}$ followed by slow evaporation. Yield: $0.11 \mathrm{~g}, 18.2 \%$. Elemental analysis (\%) calculated for $\mathrm{Co}_{15} \mathrm{NaC}_{126} \mathrm{H}_{108} \mathrm{~N}_{24} \mathrm{O}_{44} \mathrm{P}_{3} \mathrm{Cl}_{24}$ (4 with $\mathrm{MeCN}$ replaced by $\mathrm{H}_{2} \mathrm{O}$ and with $2 \mathrm{H}_{2} \mathrm{O}$ per molecule): C 33.55, H 2.41, N 7.45, found C 32.65, H 2.23, N 8.04.

Synthesis of $\left[\mathrm{Co}_{12}(\mathrm{chp})_{15}\left(\mathrm{O}_{3} \mathrm{P}^{t} \mathrm{Bu}\right)(\mathrm{F})_{3}(\mathrm{OH})_{4}\right]$ 5. Preparation as 4 except ${ }^{t} \mathrm{BuPO}_{3} \mathrm{H}_{2}(0.46 \mathrm{~g}, 0.33 \mathrm{mmol})$ was used in place of $\mathrm{EtPO}_{3} \mathrm{H}_{2}$ and crystallization was by extraction into EtOAc followed by slow evaporation. Yield: $0.12 \mathrm{~g}, 24.9 \%$. Elemental analysis (\%) calculated for $\mathrm{Co}_{12} \mathrm{C}_{79} \mathrm{H}_{66} \mathrm{~N}_{15} \mathrm{O}_{25} \mathrm{PCl}_{15} \mathrm{~F}_{3}\left(\right.$ 5. $\left.4 \mathrm{H}_{2} \mathrm{O}\right)$ : C 32.16, H 2.23, N 7.13: found C 31.58, H 1.90, N 6.70.

Synthesis of $\left[\mathrm{Co}_{6} \mathrm{Li}_{9}\left(\mathrm{PO}_{4}\right) \mathbf{C l}_{4}(\mathbf{c h p})_{14}\left(\mathrm{Hchp}_{4}\right]\right.$ 6. Preparation as 2 except LiOMe $1 \mathrm{M}$ solution in $\mathrm{MeOH}(4.66 \mathrm{~mL}, 4.66 \mathrm{mmol})$ was used in place of $\mathrm{NaOMe}$ and crystallization was by extraction into EtOAc followed by slow evaporation. Yield: $0.01 \mathrm{~g}, 1 \%$. Elemental analysis (\%) calculated for $\mathrm{Co}_{6} \mathrm{Li}_{9} \mathrm{C}_{90} \mathrm{H}_{58} \mathrm{~N}_{18} \mathrm{O}_{22} \mathrm{PCl}_{22}$ : C 36.39, $\mathrm{H}$ 2.00, N 8.49: found C 35.98, H 3.02, N 8.96.

\section{Structure determinations}

Data for compounds 2-5 were collected on a Bruker SMART CCD diffractometer CCD diffractometer (MoK $\alpha, \lambda=0.71069 \AA)$ in-house at $100 \mathrm{~K}$. Data for compound 1 were collected on a Bruker AXS SMART CCD area detector attached to station 9.8 at the CCLRC Daresbury synchrotron radiation source $(\lambda=$ $0.6932 \AA)$ at $150 \mathrm{~K}$. In all cases, the selected crystals were mounted on the tip of a glass pin using Paratone-N oil and placed in the cold flow produced with an Oxford Cryocooling device. ${ }^{11}$ Complete hemispheres of data were collected using $\omega$ scans $\left(0.3^{\circ}, 30 \mathrm{~s}\right.$ per frame). Integrated intensities were obtained with SAINT $+{ }^{12}$ and they were corrected for absorption using SADABS. ${ }^{12}$ Structure solution and refinement was performed with the SHELX-package. ${ }^{12}$ The structures were solved by direct methods and completed by iterative cycles of $\Delta F$ syntheses and full-matrix least-squares refinement against $F^{2}$. Crystal data are given in Table 1. The compounds all crystallize with solvent present in the lattice.

\section{Magnetic measurements}

The magnetic properties of polycrystalline samples were investigated using a Cryogenic M600 SQUID magnetometer and a

Table 1 Crystal data for compounds 1-6

\begin{tabular}{|c|c|c|c|c|c|c|}
\hline Compound & 1 & 2 & 3 & 4 & 5 & 6 \\
\hline Formula & $\begin{array}{l}\mathrm{Co}_{14} \mathrm{C}_{156} \mathrm{H}_{134} \mathrm{~N}_{22}- \\
\mathrm{O}_{48} \mathrm{P}_{6} \mathrm{Cl}_{30} \mathrm{Na}_{4}\end{array}$ & $\begin{array}{l}\mathrm{Co}_{6} \mathrm{C}_{102} \mathrm{H}_{83} \mathrm{~N}_{21}- \\
\mathrm{O}_{24} \mathrm{P}_{4} \mathrm{Cl}_{12} \mathrm{Na}_{8}\end{array}$ & $\begin{array}{l}\mathrm{Co}_{13} \mathrm{C}_{144.5} \mathrm{H}_{111.25^{-}} \\
\mathrm{N}_{26.75} \mathrm{O}_{42} \mathrm{P}_{5} \mathrm{Cl}_{19} \mathrm{Na}_{6}\end{array}$ & $\begin{array}{l}\mathrm{Co}_{15} \mathrm{C}_{153} \mathrm{H}_{129.5} \mathrm{~N}_{37.5-} \\
\mathrm{O}_{39.5} \mathrm{P}_{3} \mathrm{Cl}_{24} \mathrm{Na}\end{array}$ & $\begin{array}{l}\mathrm{Co}_{12} \mathrm{C}_{91} \mathrm{H}_{82} \mathrm{~N}_{15^{-}} \\
\mathrm{O}_{28} \mathrm{PCl}_{15} \mathrm{~F}_{3}\end{array}$ & $\begin{array}{l}\mathrm{Co}_{6} \mathrm{Li}_{9} \mathrm{C}_{109.5} \mathrm{H}_{100}- \\
\mathrm{N}_{18} \mathrm{O}_{23} \mathrm{PCl}_{22}\end{array}$ \\
\hline $\mathbf{M}_{r}$ & 5251.15 & 3073.67 & 4626.78 & 4976.09 & 3160.60 & 3262.99 \\
\hline Crystal system & Monoclinic & Orthorhombic & Triclinic & Monoclinic & Triclinic & Trigonal \\
\hline Space group & $P 2_{1} / n$ & $\operatorname{Pna2}_{1}$ & $P \overline{1}$ & $C 2 / c$ & $P \overline{1}$ & $P \overline{3}$ \\
\hline$a / \AA ̊$ & $18.3288(9)$ & $32.668(2)$ & $16.3367(13)$ & $49.035(3)$ & $14.7152(9)$ & $23.5886(12)$ \\
\hline$b / \AA$ & $26.0845(11)$ & $24.2542(17)$ & $17.1484(13)$ & $25.398(2)$ & $15.1602(9)$ & $23.5886(12)$ \\
\hline$c / \AA$ & $22.1377(3)$ & $16.2044(11)$ & $38.448(3)$ & $40.235(3)$ & $27.1550(17)$ & 15.9501(14) \\
\hline$\alpha /^{\circ}$ & 90 & 90 & $88.558(2)$ & 90 & $91.5620(10)$ & 90 \\
\hline$\beta /^{\circ}$ & $92.740(3)$ & 90 & $81.439(2)$ & $117.574(6)$ & $100.3280(10)$ & 90 \\
\hline$\gamma /{ }^{\circ}$ & 90 & 90 & $65.529(2)$ & 90 & $101.3280(10)$ & 120 \\
\hline$V / \AA^{3}$ & $10571.9(8)$ & $12839.5(15)$ & $9686.3(13)$ & $44417(6)$ & $5831.4(6)$ & $7686(9)$ \\
\hline$T / \mathrm{K}$ & $150(2)$ & $100(2)$ & $100(2)$ & $100(2)$ & $100(2)$ & $100(2)$ \\
\hline$Z$ & 2 & 4 & 2 & 8 & 2 & 2 \\
\hline Crystal size $/ \mathrm{mm}$ & $0.08 \times 0.08 \times 0.04$ & $0.5 \times 0.15 \times 0.15$ & $0.4 \times 0.1 \times 0.03$ & $0.2 \times 0.1 \times 0.1$ & $0.3 \times 0.3 \times 0.1$ & $0.3 \times 0.1 \times 0.1$ \\
\hline$\rho_{\text {calcd }} / \mathrm{g} \mathrm{cm}^{-3}$ & 1.650 & 1.590 & 1.586 & 1.488 & 1.800 & 1.410 \\
\hline $\begin{array}{l}\text { Crystal shape and } \\
\text { colour }\end{array}$ & Purple block & Purple needle & Purple plate & Purple plate & Purple block & Purple needle \\
\hline Radiation & Synchrotron & $\mathrm{MoK} \alpha$ & $\operatorname{MoK} \alpha$ & $\operatorname{MoK} \alpha$ & $\operatorname{MoK} \alpha$ & $\operatorname{MoK} \alpha$ \\
\hline$\lambda / \AA$ & 0.6892 & 0.7107 & 0.7107 & 0.7107 & 0.7107 & 0.7107 \\
\hline $\begin{array}{l}\text { Total reflec- } \\
\text { tions/independent } \\
\text { reflections }\end{array}$ & $38913 / 17235$ & $73251 / 25786$ & $50628 / 33643$ & $31826 / 31826$ & $33572 / 23033$ & $45119 / 10519$ \\
\hline$R_{\text {int }}$ & 0.0846 & 0.0316 & 0.0384 & 0 & 0.0227 & 0.0465 \\
\hline $\begin{array}{l}\text { Reflections with } \\
I>2 \sigma(I)\end{array}$ & 11997 & 23521 & 21956 & 15308 & 20031 & 7965 \\
\hline Parameters & 1303 & 1603 & 2492 & 2346 & 1601 & 598 \\
\hline Restraints & 42 & 1 & 682 & 1428 & 375 & 553 \\
\hline$R_{1}, \mathrm{w} R_{2}^{a}$ & $0.0621,0.166$ & $0.0361,0.0809$ & $0.0688,0.2215$ & $0.0797,0.2123$ & $0.0338,0.0907$ & $0.0537,0.1736$ \\
\hline Goodness of fit & 0.998 & 1.055 & 1.029 & 0.938 & 0.909 & 0.956 \\
\hline Largest residuals/e $\AA^{-3}$ & $1.187,-0.742$ & $1.185,-1.113$ & $1.427,-1.035$ & $0.926,-0.642$ & $1.410,-1.450$ & $1.626,-1.033$ \\
\hline
\end{tabular}


home-developed ac probe based on the Oxford Inst. MAGLAB platform. ${ }^{13}$

\section{Results}

The starting point for this chemistry was the reaction of hydrated cobalt nitrate with two equivalents of 6-chloro-2-hydroxypyridine (Hchp), one-sixth of an equivalent of $\mathrm{PhPO}_{3} \mathrm{H}_{2}$ and two and onethird equivalents of sodium methoxide. The components were mixed in $\mathrm{MeOH}$, the solution evaporated to dryness and extracted with $\mathrm{CH}_{2} \mathrm{Cl}_{2}$; crystals could be grown by layering with hexanes.

The complex that results in $c a$. 30\% yield, has the formula $\left[\mathrm{Co}_{14} \mathrm{Na}_{4}(\mathrm{chp})_{20}\left(\mathrm{O}_{3} \mathrm{PPh}\right)_{6}(\mathrm{Hchp})_{2}\left(\mathrm{H}_{2} \mathrm{O}\right)_{8}\right]$ 1. The structure is complex and irregular and lies about an inversion centre (Fig. 1). Ten of the cobalt centres make up a distorted ring, with the four remaining sites lying above and below the plane of the ring. The distorted ring can be considered as an irregular octagon, with three metal sites on two edges ( $\mathrm{Co} 1, \mathrm{Co} 2$ and $\mathrm{Co} 5 \mathrm{a}$ in one case, and their symmetry equivalents on the second three metal edge). The other edges of the octagon contain two metals, e.g. Co5 and $\mathrm{Co} 4$ or $\mathrm{Co} 4$ and $\mathrm{Co} 3$ or $\mathrm{Co} 3$ and $\mathrm{Co} 2$. The final four cobalt sites (Co6, $\mathrm{Co} 7$ and the symmetry equivalents) lie in pairs above the Co3-Co4 and Co3a-Co4a edges. Within the macrocycle are four sodium ions which form a rhombus.

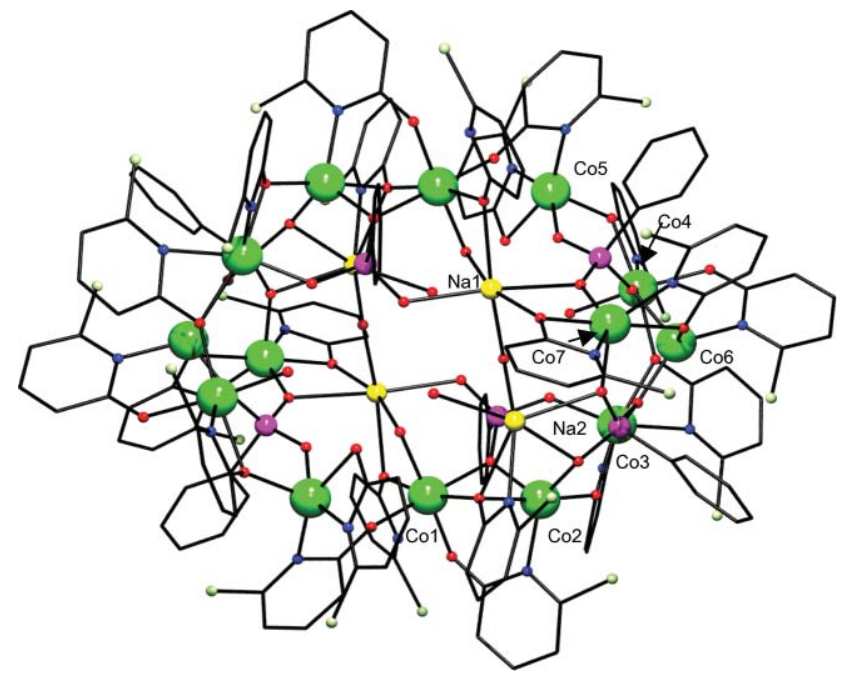

Fig. 1 The structure of 1 in the crystal. Colour scheme: $\mathrm{Co}=$ green; $\mathrm{P}=$ magenta; $\mathrm{N}=$ blue; $\mathrm{O}=$ red; $\mathrm{C}=$ black lines; $\mathrm{Cl}=$ light green; $\mathrm{Na}=$ yellow.

There are six bridging phosphonates, which display three different modes of bonding. These are 5.222, 5.221 and 4.211 (Harris notation ${ }^{14}$ - see Scheme 1). There are eight water molecules within the cage, four are bridging and four are terminal. O4W bridges $\mathrm{Na} 1$ to $\mathrm{Na} 2$, while $\mathrm{O} 1 \mathrm{~W}$ bridges $\mathrm{Co} 1 \mathrm{~A}$ to $\mathrm{Na} 1$, the terminal waters are bound to $\mathrm{Na} 2, \mathrm{Co} 4$ and the symmetry equivalent sites. The chp ligands bind on the outside of the cage: two display the 3.31 mode, eight the 2.21 , four the 2.20 , six the 2.11 and two adopt the 1.11 bonding mode. Two of the cobalt sites are four-coordinate, six are five-coordinate and six are sixcoordinate with distorted tetrahedral, trigonal bipyramidal and octahedral geometries respectively. The four sodium ions are all six

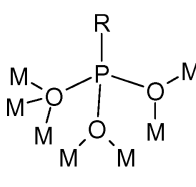

7.322<smiles>[M]O[PH]([R])(O[M])O[M]</smiles>

6.222<smiles>[M]O[PH]([R])(O[M])O[M]</smiles>

5.222<smiles>[M]O[PH]([R])(O[M])O[M]</smiles><smiles>[M]O[PH]([R])(O[M])O[M]</smiles>

Scheme 1

coordinate. $\mathrm{Na} 2$ and $\mathrm{Na} 2 \mathrm{a}$ have distorted octahedral geometries, while $\mathrm{Na} 1$ and $\mathrm{Nala}$ have more regular octahedral geometries.

Use of hydrated cobalt chloride in place of hydrated cobalt nitrate gives a different product; crystallization conditions also had to be changed so that $\mathbf{2}$ was crystallised by slow evaporation of a MeCN solution. The yield $(\mathrm{ca} .7 \%)$ is much lower than for 1. X-Ray structural analysis shows a cage with formula $\left[\mathrm{Co}_{6} \mathrm{Na}_{8}(\mathrm{chp})_{12}\left(\mathrm{O}_{3} \mathrm{PPh}\right)_{4}(\mathrm{MeCN})_{4}\right]$ 2. Compound 2 (Fig. 2) is a heterometallic tetradecanuclear cage containing six $\mathrm{Co}$ (II) ions and eight $\mathrm{Na}$ ions. The central part of the structure consists of a $\left\{\mathrm{Na}_{4} \mathrm{P}_{4}\right\}$ heterocubane. The four $\mathrm{P}$ atoms [P1-P4] derived from the phosphonate are found at alternate corners of the cube, with $\mathrm{Na}$ atoms [Na1-Na4] at the other corners. The six Co(II) ions [Co1-Co6] are found above each face of the cube - hence forming an octahedron, while the final four $\mathrm{Na}$ atoms lie above four of the edges of the cube. The assembly of $\mathrm{P}, \mathrm{Na}$ and $\mathrm{Co}$ has noncrystallographic $D_{2 \mathrm{~d}}$ symmetry.

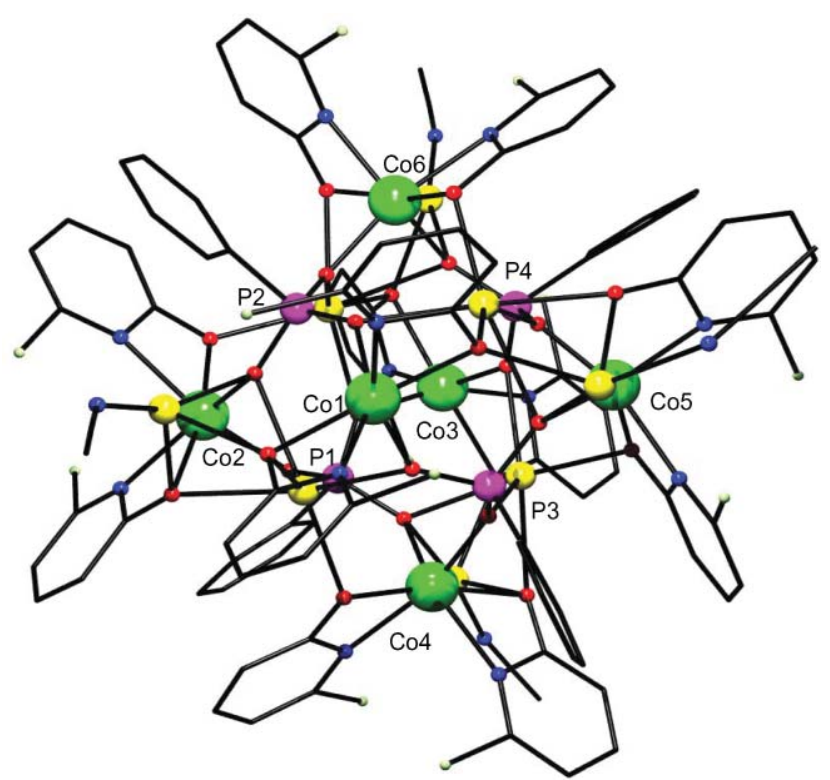

Fig. 2 The structure of $\mathbf{2}$ in the crystal. Colour scheme as Fig. 1.

The four phosphonates in $\mathbf{2}$ show the 7.322 bridging mode. The $\mu_{3}-\mathrm{O}$ atom bridges two $\mathrm{Na}$ and one $\mathrm{Co}$, while the two $\mu_{2}$-oxygen atoms bridge between one $\mathrm{Na}$ and one $\mathrm{Co}$ site. The chp ligands 
adopt the 2.21, 3.21 and 3.31 bridging modes, chelating to a cobalt site and additionally binding to either one or two $\mathrm{Na}$ ions. Five of the cobalt sites are six-coordinate with irregular octahedral geometries, while the sixth is five-coordinate with an irregular trigonal bipyramidal geometry. The coordination of $\mathrm{Na}$ ions is still more irregular. The four $\mathrm{Na}$ sites within the cube are sixcoordinate, while the four "capping" Na sites are four-coordinate.

Use of benzylphosphonic acid rather than phenylphosphonic acid gives a third compound, which $\mathrm{X}$-ray analysis shows to have the formula $\left[\mathrm{Co}_{13} \mathrm{Na}_{6}(\mathrm{chp})_{19}\left(\mathrm{O}_{3} \mathrm{PPh}\right)_{5}(\mathrm{OH})_{2}\left(\mathrm{NO}_{3}\right)\right.$ $\left.(\mathrm{MeCN})\left(\mathrm{H}_{2} \mathrm{O}\right)(\mathrm{MeOH})\right]$ 3. Frustratingly this compound forms from the same cobalt salt as $\mathbf{1}$, but using the crystallisation conditions employed for $\mathbf{2}$. This makes it difficult to understand how specific factors are influencing the products formed. Compound $\mathbf{3}$ (Fig. 3) crystallises in the triclinic $P \overline{1}$ and contains thirteen $\mathrm{Co}(\mathrm{II})$ ions and six $\mathrm{Na}$ ions. The structure has an entirely inexplicableand indescribable - core. There appears to be no repeating motif, and certainly there are no symmetrical polyhedra present. The six phosphonates show two bonding modes: three have the 5.222 mode (chelating to a $\mathrm{Na}$ ion) and two the 5.221. Therefore in each case they bridge to five different metals - creating distorted pentagonal building blocks. Müller has identified such blocks as key components in the synthesis of nanoscale polyoxomolybdate structures,${ }^{15}$ however whether the pentagons are important here is debatable. A nitrate ion is found inside the cage adopting a 7.322 bonding mode, which is quite unusual, it binds to three $\mathrm{Na}$ ions and four cobalt ions. Nine cobalt ions and five sodium ions are six-coordinate, while four cobalt and one sodium are five-coordinate. The geometries are irregular. It is probably the combination of two metal ions with irregular geometries, and the pentanucleating phosphonate ligands, and the presence of chp, which is also extremely unselective in its binding modes, that combine to create the indescribable metal core. The chp ligands show several binding modes: seven are 3.31 , one is 3.21 , ten are 2.21 and there is a single chp that is 2.11. These ligands are found on the exterior of the cage.

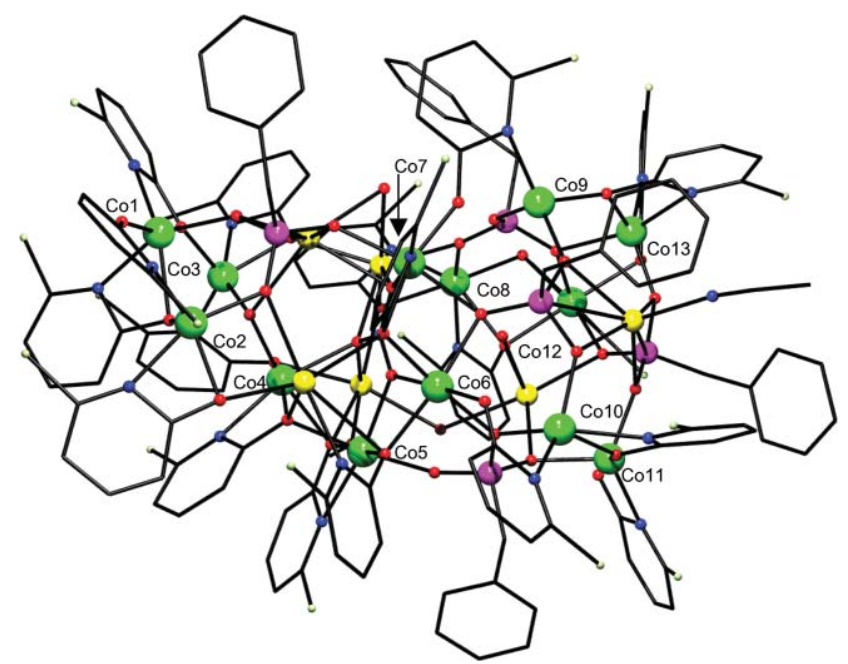

Fig. 3 The structure of $\mathbf{3}$ in the crystal. Colour scheme as Fig. 1.

To crystallise compounds with further phosphonic acids we had to change the cobalt salt to hydrated cobalt tetrafluoroborate. This allowed crystallisation of compounds with both ethylphospho- nic acid $\left(\mathrm{EtPO}_{3} \mathrm{H}_{2}\right)$ and tert-butylphosphonic acid $\left({ }^{t} \mathrm{BuPO}_{3} \mathrm{H}_{2}\right)$, however even here direct comparison is impossible as different solvents had to be used to grow crystals. For example, with $\mathrm{EtPO}_{3} \mathrm{H}_{2}$ we could crystallise compound 4 by evaporation of $\mathrm{MeCN}$, but when ${ }^{t} \mathrm{BuPO}_{3} \mathrm{H}_{2}$ was used crystals could only be grown from EtOAc (compound 5)., The cages have the formulae $\left[\mathrm{Co}_{15} \mathrm{Na}(\mathrm{chp})_{22}(\mathrm{Hchp})_{2}\left(\mathrm{O}_{3} \mathrm{PEt}\right)_{3}(\mathrm{OH})_{3}\left(\mathrm{H}_{2} \mathrm{O}\right)_{3}(\mathrm{MeCN})_{3}\right] 4$ and $\left[\mathrm{Co}_{12}(\mathrm{chp})_{15}\left(\mathrm{O}_{3} \mathrm{P}^{t} \mathrm{Bu}\right)(\mathrm{F})_{3}(\mathrm{OH})_{4}\right] 5$.

Complex 4 (Fig. 4) is a heterometallic hexadecanuclear cage, consisting of fifteen $\mathrm{Co}(\mathrm{II})$ ions and a single sodium ion. Compound 4 crystallises in the $C 2 / c$ space group. The cage has non-crystallographic three-fold symmetry. The structure is again irregular. To describe it we can consider the central sodium ion to belong to three linked hexametallic sub-units, each of which adopts a distorted boat conformation. The first boat is made up of (Na1, Co2-Co5 and Co7), the second (Na1, Co4, Co6 and Co12-Co14) and the third (Na1 and Co7-Co12). This accounts for twelve of the cobalt sites. The final three cobalt centres (Col, Co15 and Co9) each lie above a boat. There are three phosphonates within the structure all show the 6.222 bonding mode and bind to the five cobalt sites and sodium ion that make up individual hexametallic sub-units. There are three $\mu_{2}$-water molecules that bridge from the central sodium ion to $\mathrm{Co} 4, \mathrm{Co} 7$ and $\mathrm{Co} 12$; similar bridges were found in $\mathbf{2}$. There are three $\mu_{2}$-hydroxides that bridge $\mathrm{Co} 3, \mathrm{Co}$, $\mathrm{Co} 7$ to $\mathrm{Co} 5, \mathrm{Co} 14, \mathrm{Co} 11$, respectively. The twenty-four chp ligands present utilize four modes of bonding: twelve are 2.21, six 2.20, three 3.21 and three are 1.10. The three terminal MeCN ligands that are present complete the coordination spheres for $\mathrm{Co} 1, \mathrm{Co} 9$ and Co15. Thirteen of the cobalt ions are six-coordinate with distorted octahedral geometries and two are five-coordinate with square pyramidal geometries. The sodium ion is also sixcoordinate with a distorted octahedral geometry. The elemental analysis of $\mathbf{4}$ is not very good, and suggests that partial replacement of the $\mathrm{MeCN}$ molecules in the structure with $\mathrm{H}_{2} \mathrm{O}$ takes place in the solid state.

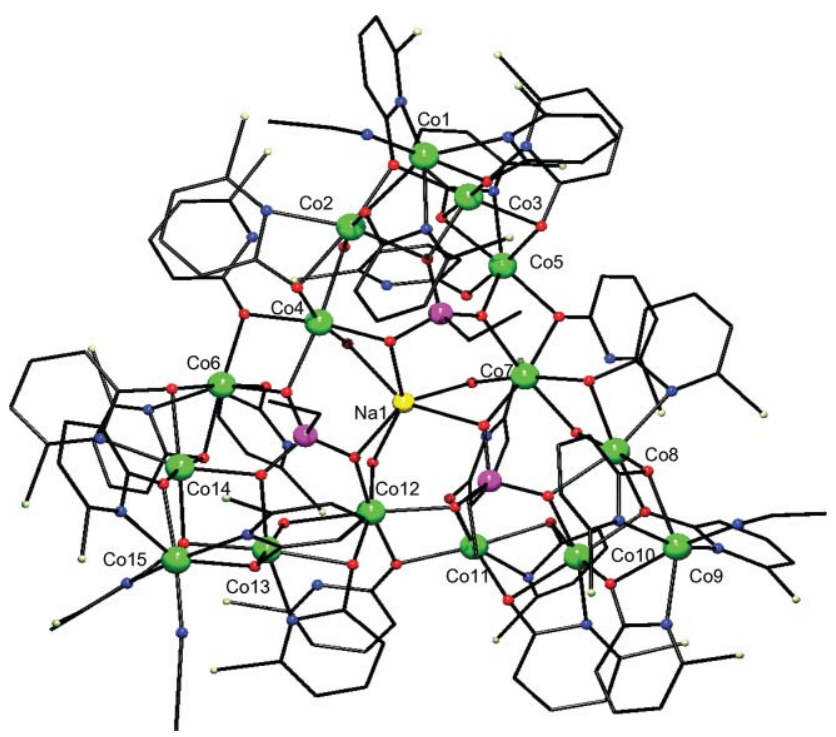

Fig. 4 The structure of $\mathbf{4}$ in the crystal. Colour scheme as Fig. 1.

Compound 5 (Fig. 5) is a dodecanuclear Co(II) cage, which crystallises in the $P \overline{1}$ space group, and has non-crystallographic 


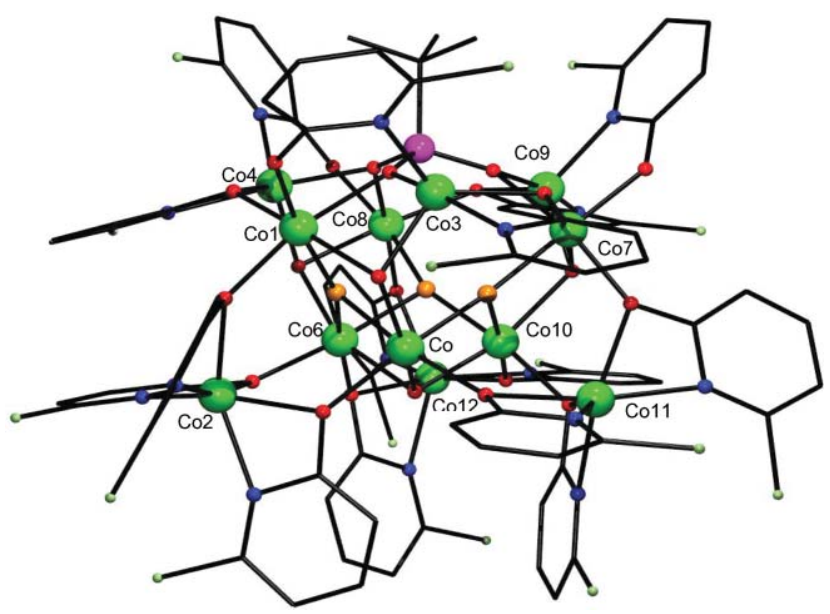

Fig. 5 The structure of 5 in the crystal. Colour scheme as Fig. 1, plus F = orange.

three-fold symmetry. This cage is the first in this series not to contain the sodium ion within the core. The metal core has noncrystallographic three-fold symmetry and can be described as a related to a cuboctahedron missing one triangular face; nine of the Co sites (all except Co2, Co11 and Co12) lie on the vertices of this polyhedron. The single phosphonate occupies the area that would be occupied by the missing face of a complete cuboctahedron; it lies on the three-fold axis, and adopts the 6.222-bridging mode, binding to $\mathrm{Co} 1, \mathrm{Co} 3, \mathrm{Co} 4, \mathrm{Co} 7, \mathrm{Co} 8$ and Co9. Alternate edges, which form part of the triangular faces of the incomplete cuboctahedron $(\mathrm{Co} 1 \cdots \mathrm{Co} 3, \mathrm{Co} 4 \cdots \mathrm{Co} 8, \mathrm{Co} 7 \cdots \mathrm{Co} 9)$, are bridged by a $\mu_{2}$-oxygen from the phosphonate, a 2.11 bridging chp ligand, and a $\mu_{3}$-monoatom bridge (O19, $\mathrm{O} 20$ and $\mathrm{O} 21$, respectively), which we have assigned as a hydroxide and which lies near the centre of the triangular face. The other Co ... Co edges of the hexagon are bridged by 2.21 bound pyridonates. The $\mathrm{N}$-atoms from the six chp ligands associated with the hexagon are bound to three of the $\mathrm{Co}$ sites (Co3, Co4, Co9). These three sites are five-coordinate. The other three sites in the hexagon are six-coordinate, and are bound to a further monoatom ligand, which we have assigned as fluoride (F1, F2, F3), and which bridge to Co sites (Co5, Co6 and Co10) from the capping triangle of the cuboctahedron.

This triangle of cobalt sites are attached to the hexagon through six monoatom bridges (three $\mathrm{OH}$ and three fluoride). The $\mathrm{F}$ ligands are within the rectangular face of the cuboctahedron while the $\mathrm{OH}$ lie within the triangular faces. The groups are assigned as $\mathrm{F}$ based on X-ray refinement, where these atoms had abnormally small anisotropic displacement parameters if refined as hydroxide. The formation of fluoride from tetrafluoroborate is not uncommon ${ }^{16}$ and has been seen previously in related chemistry. ${ }^{17}$ The geometries at the two monoatom bridges are very different. For each $\mathrm{OH}$ sites there are three distinct bond angles: one around $89^{\circ}$, one around $98^{\circ}$ and one around $120^{\circ}$, giving a distorted pyramidal geometry at the $\mathrm{OH}$. For each $\mathrm{F}$ site, two bond angles are close to $100^{\circ}$, with the third near $158^{\circ}$; this gives a planar T-shaped geometry at the fluoride. A seventh monoatom ligand - assigned as $\mathrm{OH}-$ bridges between the three sites of the capping triangle. This has three equivalent $\mathrm{Co}-\mathrm{O}-\mathrm{Co}$ bond angles of around $98^{\circ}$, giving a pyramidal geometry.
The final three Co sites (Co2, Co11 and Co12) are each bound to three 2.21-bridging pivalates; previously we have described such fragments as $\left[\mathrm{Co}(\mathrm{chp})_{3}\right]^{-}$complex ligands. ${ }^{10}$ The three $\mathrm{O}$-atoms from each such fragment bind to three of the four Co centres within a rectangular face of the cuboctahedron. The coordination geometries at all the Co sites in the structure are distorted.

Attempts to use LiOMe as base to see if further novel cages could be produced which contained the lithium ion were largely unproductive, with one exception. A cage with the formula $\left[\mathrm{Co}_{6} \mathrm{Li}_{9}\left(\mathrm{PO}_{4}\right) \mathrm{Cl}_{4}(\mathrm{chp})_{14}(\mathrm{Hchp})_{4}\right] 6$ could be isolated using phenylphosphonic acid followed by crystallization from EtOAchexane. Compound 6 (Fig. 6) is a heterometallic pentadecanuclear cage which crystallises in the trigonal $P \overline{3}$ space group. 6 consists of nine lithium ions and six $\mathrm{Co}$ (II) ions. The structure has crystallographic three-fold symmetry. At the centre is a bridging phosphate, which adopts the 12.3333 bridging mode: one O-atom binds to three cobalt atoms [Co1, $\mathrm{Co} 2$ and $\mathrm{Co} 3$ ], while the others bind to three lithium centres. The twelve metals bound to the $\mathrm{PO}_{4}{ }^{3-}$ lie on the vertices of an icosahedron. The metal-metal contacts within this polyhedron vary with $\mathrm{Li} \cdot \mathrm{Li}$ contacts lying in the range $3.03-3.28 \AA$, the Co $\cdots$ Co contact $3.22 \AA$ and the Co $\cdots \mathrm{Li}$ contacts ranging from 3.33-3.77 $\AA$. The final three Co centres, [Co4, Co5 and Co6] are found outside the icosahedron, lying on points of an equilateral triangle (Fig. 7). Four $\mu_{3}$-chloride ions are also found, these lie on the points of a tetrahedron, with three bridging to one $\mathrm{Co}$ and two $\mathrm{Li}$ atoms, and the fourth (which lies on the three fold axis) bridging three $\mathrm{Li}$ centres. The $\mathrm{Li}$ centres are all four coordinate with tetrahedral geometries while the Co centres are all six coordinate with distorted octahedral geometries. The distortion is chiefly due to the presence of chelating chp ligands, with a narrow 'bite' angle; the pyridonates show the 2.21 binding mode, while the Hchp ligands present are 2.20. An interesting aspect of this compound is the bridging phosphate at the centre of the icosahedron. The phosphate $\left(\mathrm{PO}_{4}{ }^{3-}\right)$ is not one of the starting materials and appears to have been derived from phenyl phosphonic acid which undergoes oxidation in situ. The

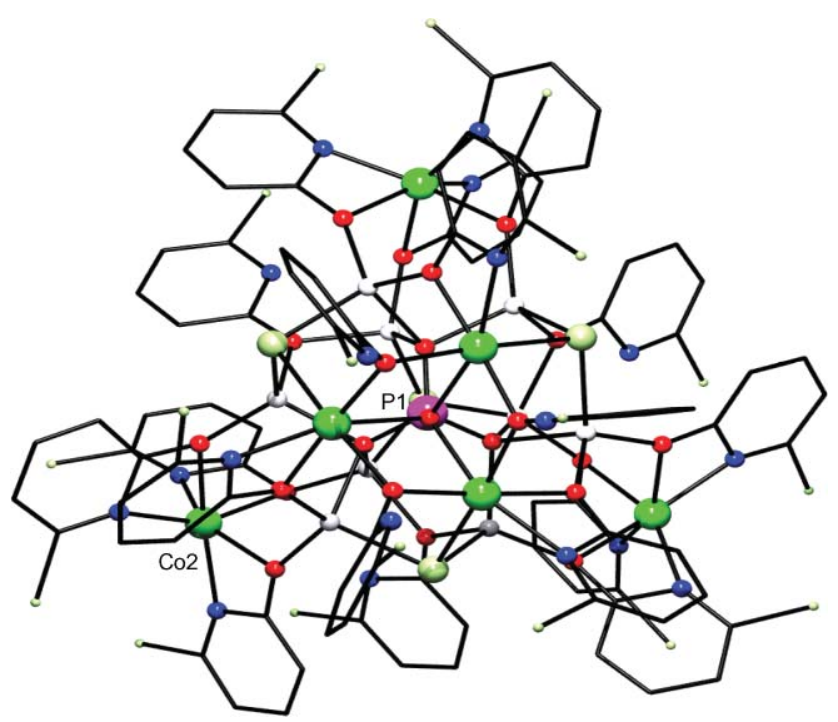

Fig. 6 The structure of 6 in the crystal. Colour scheme as Fig. 1, plus $\mathrm{Li}=$ silver, $\mathrm{Cl}=$ light green. 


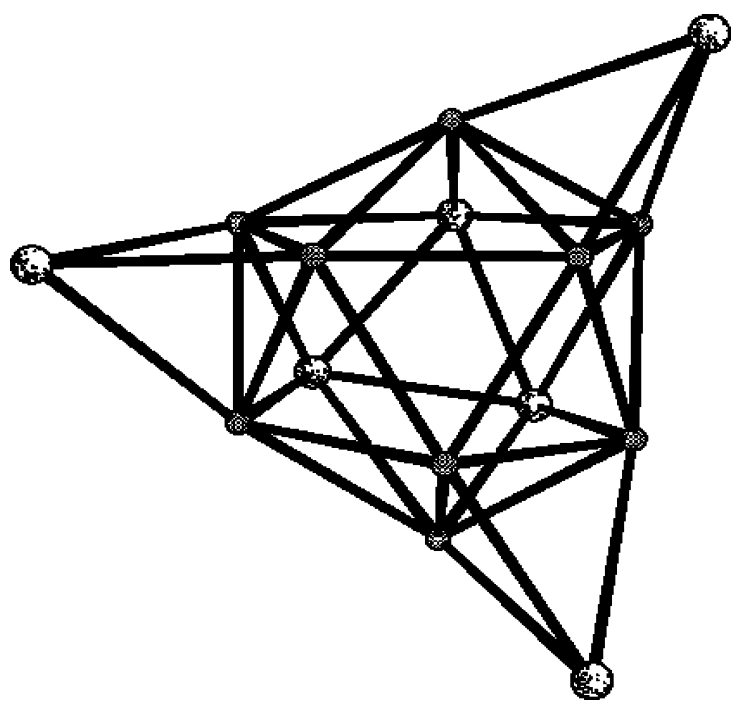

Fig. 7 Icosahedron core of 6.

yield of this compound is too low to allow magnetic studies to be performed

\section{Magnetic measurements}

The variable temperature magnetic behaviour of $\mathbf{1}-\mathbf{5}$, represented as $\chi_{\mathrm{m}} T$ against $T$ (where $\chi_{\mathrm{m}}$ is the molar magnetic susceptibility), is shown in Fig. 8. To make comparisons between the different clusters easier the data is plotted per cobalt centre. The data per formula unit is given in the ESI. $\dagger$ Explanation of magnetic behaviour of cobalt(II) complexes is always difficult, due to the orbital degenerate ground state of the ion when six-coordinate. For this reason derivation of the magnitude of the exchange interactions between cobalt centres is impossible-especially in cases such as those here where the structures are extremely complicated-and even assigning a "spin" ground state to such clusters is largely meaningless. Therefore only a qualitative report of the magnetic susceptibility data can be made.

Four of the five compounds show a steady decrease in $\chi_{\mathrm{m}} T$ as $T$ falls, with compound $\mathbf{4}$ showing a less notable decrease as the temperature drops. The decrease of $\chi_{\mathrm{m}} T$ as temperature is lowered is probably due to single ion effects of $\mathrm{Co}(\mathrm{II})$. Below about $30 \mathrm{~K}$ the behaviour of the clusters diverges. (Fig. 8b). For cages 1 and $\mathbf{2}$ we see the value of $\chi_{\mathrm{m}} T$ continuing to fall at very low temperatures which may indicate a diamagnetic ground state. Compounds 3, 4 and 5 each exhibit a maximum at $c a$. $6 \mathrm{~K}$, and we assume that these maxima reflect a non-zero ground state spin for these cages. However given the strong spin-orbit coupling in Co(II) centre it makes little sense to assign a "spin ground state". Magnetisation studies do not help (see ESI $\dagger$ ) as none of the compounds saturate at high fields and low temperature. Given the high anisotropy of the ions present and the high nuclearity of the clusters with many spin states populated at low temperature this is unsurprising.

Ac measurements were performed on compounds 3-5 as these compounds showed a maximum in the $\chi_{\mathrm{m}} T$ vs. $T$ curve. Compound $\mathbf{4}$ did not produce anything of note, however $\mathbf{3}$ and $\mathbf{5}$ both showed a frequency dependent maxima peak in $\chi^{\prime \prime}$ and $\chi^{\prime}$ against $T$ (Fig. 9 and 10), where $\chi^{\prime \prime}$ is the out-of-phase and $\chi^{\prime}$ is the in-phase susceptibility. The two curves for $\mathbf{3}$ and $\mathbf{5}$ however
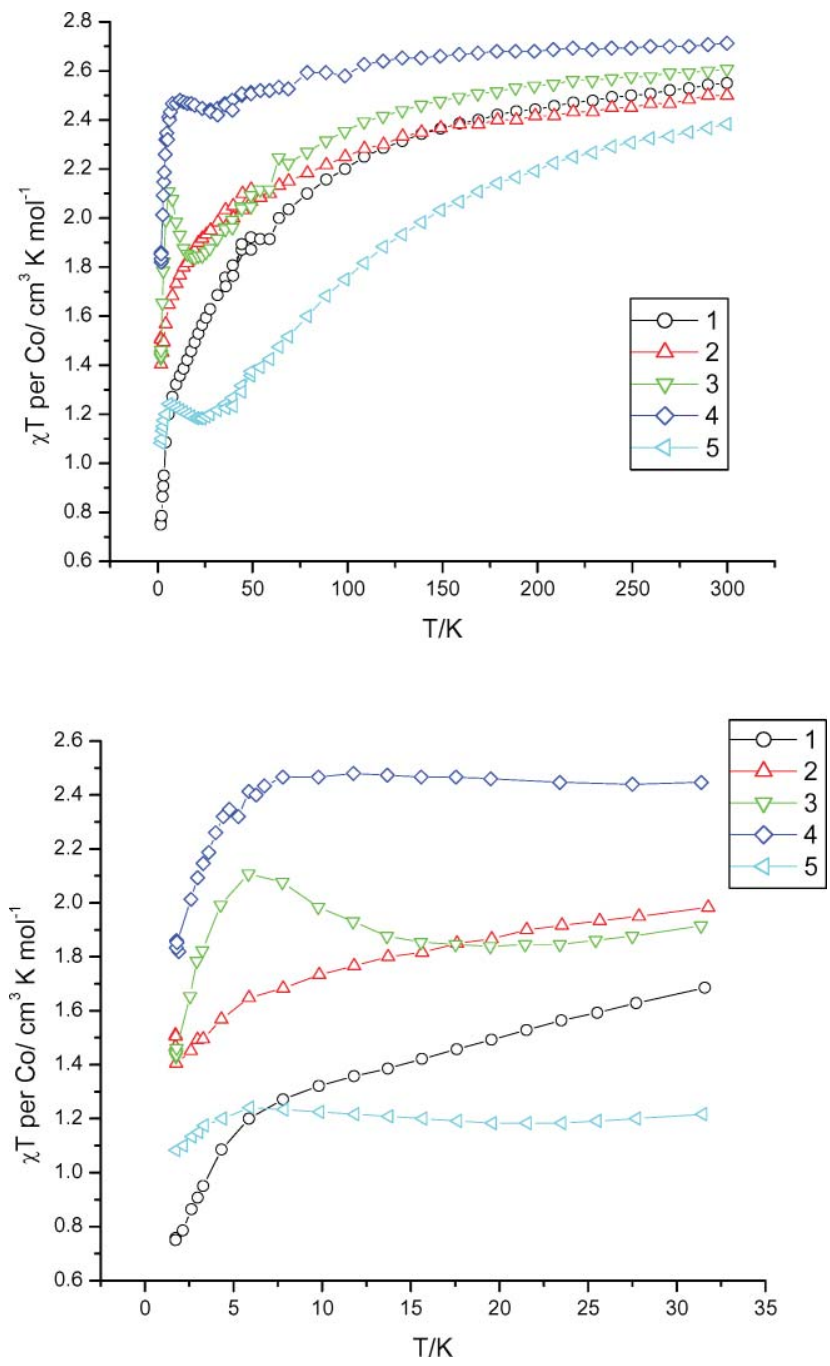

Fig. 8 Variation of $\chi_{\mathrm{m}} T$ per cobalt with $T$ for compounds 1-5 measured at $1000 \mathrm{G}$; (a) from $300-2 \mathrm{~K}$; (b) from $35-2 \mathrm{~K}$.

are different at the temperatures studied. 3 shows a frequency dependent peak in $\chi^{\prime \prime}$ against $T$ and a second rise in $\chi^{\prime \prime}$ at lower temperature. 5 shows a rise in $\chi^{\prime \prime}$ as the temperature falls, but we were unable to observe a maximum at any frequency above $1.8 \mathrm{~K}$, which was the limit of the equipment.

The behaviour of $\mathbf{3}$ is similar to the data we recorded on an octanuclear $\mathrm{Co}$ (II) cage; there we extended our studies to lower temperature and found a second maximum at $1.5 \mathrm{~K}$. If the peaks in $\chi^{\prime \prime}$ are used to extract a relaxation time according to the assumption that at the temperature of the maximum $\tau=(2 \pi \nu)^{-1}$, physically meaningless values for the Arrhenius plot are obtained: a barrier of $54 \mathrm{~K}$ with a pre-exponential factor of $10^{-25} \mathrm{~s}$. It is however important to remember that a more accurate analysis should be based on the frequency dependence of $\chi^{\prime \prime}$. As shown in Fig. 11, this has a very peculiar behaviour. It is zero for the whole investigated frequency range for temperatures above $5 \mathrm{~K}$. At lower temperatures, the typical increase with increasing frequency is observed. However, no maxima are observed, and for intermediate temperatures around $3 \mathrm{~K}$, very flat and temperature independent curves are observed. Only at below $2.3 \mathrm{~K}$ is a pronounced temperature dependence re-established, but again no maxima are 


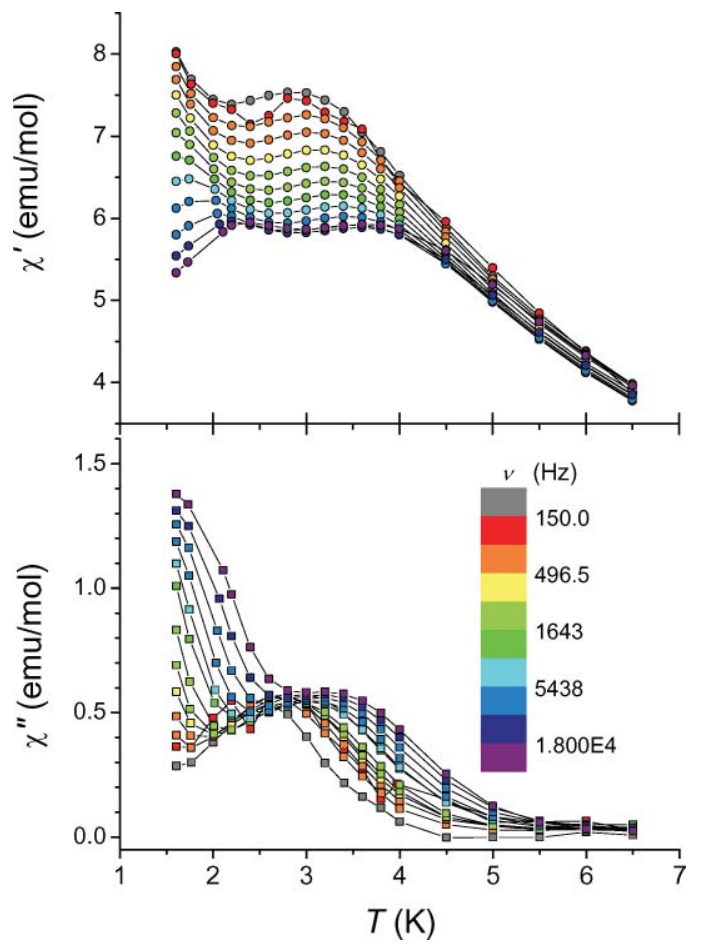

Fig. 9 Temperature dependence of the real (top) and imaginary (bottom) components of the ac susceptibility of $\mathbf{3}$ in zero static field for frequencies ranging between $100 \mathrm{~Hz}$ and $20 \mathrm{kHz}$ (see colour scale in the legend). Lines are only a guide.

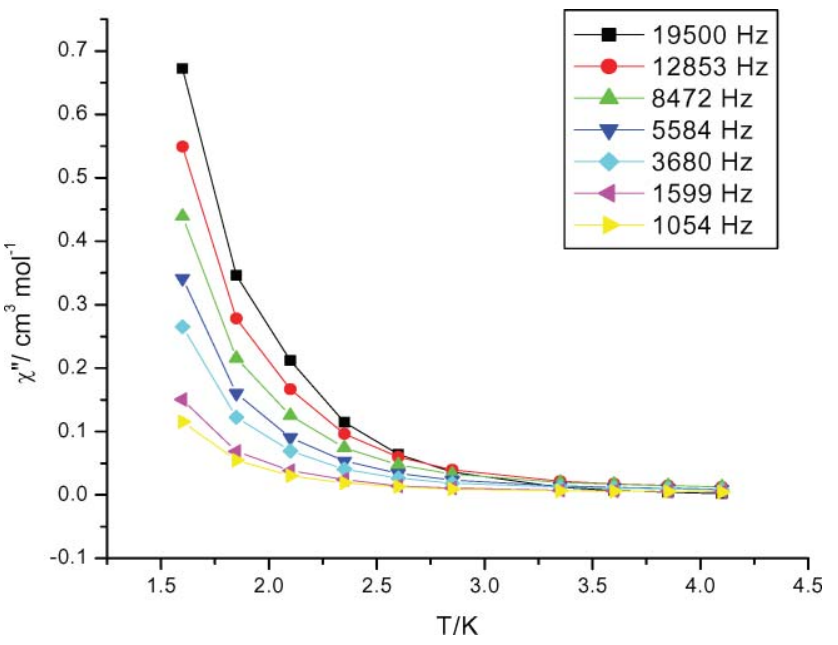

Fig. 10 Frequency dependent behaviour of $\chi^{\prime \prime}$ for 5 .

observed suggesting that the relaxation rate exceeds $20 \mathrm{kHz}$. Such behaviour suggests that in the intermediate temperature regime there is a tunnelling mechanism with a very large distribution of relaxation times, as revealed by the large $\chi^{\prime} / \chi^{\prime \prime}$ ratio, while at lower temperature a thermally activated mechanism dominates. At present it is not possible to assess if different components of the magnetisation, or different parts of the clusters are responsible for the two types of relaxation observed. Undoubtedly, cobalt clusters seem to show a much more complex magnetisation dynamics and tunnelling effects are more relevant than for clusters based on orbital non-degenerate ions.

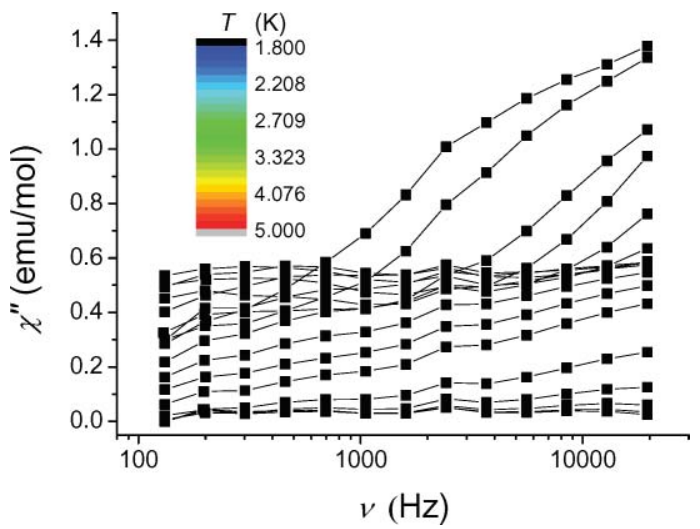

Fig. 11 Frequency dependence of $\chi^{\prime \prime}$ for 3 between 1.7-5.0 K (see colour scale in the legend). Lines are only a guide to the eyes.

\section{Conclusions}

It is unusual to find large polynuclear cobalt cages - for example only six cages with nuclearities greater than twelve have been reported prior to our work with phosphonates. ${ }^{18}$ Here, phosphonate ligands have been used, in conjunction with 2-chloro6-hydroxypyridine, to make new compounds containing six, twelve, thirteen, fourteen and fifteen cobalt centres; it is safe to say that phosphonates can be used successfully to make large cages.

It is worth stressing that only products which crystallize could be properly characterized; these compounds do not give good mass spectra, for example, and therefore use of electrospray mass spectroscopy to characterize solution species was not possible. This also means that we cannot be sure which factors govern formation of the cages that are formed-it seems likely that in solution an equilibrium is present and that crystallization conditions decide which species are seen. This means that, at this stage of these studies, we can say nothing of value about the mechanisms by which these compounds form.

The structures do not fall into simple families of cages, nor do common structural motifs appear in the various compounds. In our previous paper ${ }^{1}$ we showed that where triethylamine is used as a base a common feature was the formation of a cobalt hydroxide plane, similar to that found in cobalt hydroxide itself. Here, we see no fragments related to the mineral. The two $\left\{\mathrm{Co}_{6}\right\}$ cages $-\mathbf{2}$ and 6 - have quite regular structures, where the position of the metal sites, cobalt and sodium in $\mathbf{2}$ and cobalt and lithium in $\mathbf{6}$, can be considered to lie on the vertices of Platonic solids. The larger cages are much less regular, and in the case of $\mathbf{3}$ indescribable.

This lack of regularity and lack of common motifs indicates a lack of any strong structure directing component within the reaction matrix. Neither cobalt(II) nor sodium has a strong preference for a specific coordination number or geometry, while the two ligands - phosphonate and chp — both show remarkable flexibility in their coordination modes. In the structures reported here, the phosphonate ligands use five different modes of bonding: $7.322,6.222,5.222,5.221,4.211$. Additionally a phosphate ligand, formed from decomposition of a phosphonate, adopts the 12.3333 bonding mode. The chp ligands show the 3.31, 3.21, 2.21, 2.20, $2.11,1.11,1.10$ modes. This suggests that in future work addition of a templating agent to this cobalt/sodium/phosphonate/chp 
Table 2 Bond length ranges ${ }^{a}$ by bonding mode and coordination number

\begin{tabular}{|c|c|c|c|}
\hline & Four-coordinate $\mathrm{Co}(\mathrm{II})$ & Five-coordinate $\mathrm{Co}(\mathrm{II})$ & Six-coordinate Co(II) \\
\hline \multicolumn{4}{|l|}{$\operatorname{chp}$} \\
\hline $1.10^{a}$ & - & $2.004-2.007$ & - \\
\hline 1.11 & - & 2.193 & - \\
\hline 1.11 & - & 2.157 & - \\
\hline 2.11 & - & - & $1.994-2.092$ \\
\hline 2.11 & - & $2.056-2.089$ & - \\
\hline 2.20 & - & $2.035-2.105$ & $2.022-2.177$ \\
\hline 2.21 & 2.011 & $1.991-2.314$ & $2.013-2.409$ \\
\hline 2.21 & - & $2.056-2.234$ & $2.058-2.246$ \\
\hline 3.21 & - & $2.023-2.111$ & 2.059 \\
\hline 3.21 & - & 2.055 & $2.103-2.140$ \\
\hline 3.31 & - & $2.040-2.214$ & $2.070-2.332$ \\
\hline 3.31 & - & 2.357 & $2.140-2.261$ \\
\hline \multicolumn{4}{|l|}{$\mathrm{PO}_{3}{ }^{2}-$} \\
\hline 4.211 & - & 2.016 & 2.182 \\
\hline 4.211 & - & - & 2.012 \\
\hline 5.221 & 1.974 & $1.977-2.034$ & $1.989-2.091$ \\
\hline 5.221 & - & 2.008 & $1.992-2.013$ \\
\hline 5.222 & 2.003 & $1.930-1.989$ & $1.968-2.174$ \\
\hline 6.222 & - & $2.004-2.087$ & $2.007-2.202$ \\
\hline 7.322 & - & 2.023 & $2.041-2.055$ \\
\hline 7.322 & - & - & $2.007-2.041$ \\
\hline
\end{tabular}

$\mathrm{PO}_{4}{ }^{3-}$

12.3333

$-$

2.199

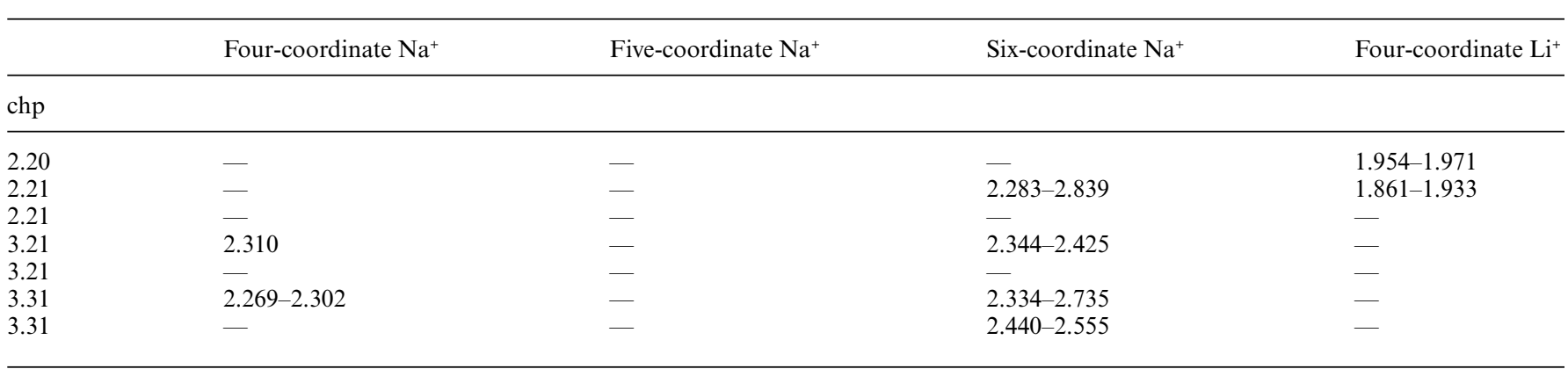

$\mathrm{PO}_{3}{ }^{2}-$

\begin{tabular}{lllll}
\hline 4.211 & - & - & - & - \\
4.211 & - & - & 2.353 & - \\
5.211 & - & - & $2.354-2.480$ & - \\
5.211 & - & $2.386-2.412$ & $2.360-2.549$ & - \\
5.222 & - & - & $2.374-2.404$ & - \\
6.222 & - & - & $2.384-2.508$ & - \\
7.322 & - & - & $2.314-2.446$ & - \\
7.322 & & & \\
\hline
\end{tabular}

$\mathrm{PO}_{4}{ }^{3-}$

12.3333

-

$-$

$1.958-2.024$

${ }^{a}$ The e.s.d.s fall in the range $0.002-0.019 \AA$ A. With e.s.u's in the range [(2)-(10)]. ${ }^{b}$ Harris notation follows Cahn-Ingold-Prelog priority rules, therefore for chp the second number refers to the number of metal centres bound to the $\mathrm{O}$-atom and the third number the number bound to the $\mathrm{N}$-atom. The bold number indicates the atom involved in the bond length in the table.

mixture might allow controlled synthesis of specific structures as none of the current components have any strong structure directing preferences. A summary of the bond lengths for the various metal ions and ligands is given in Table 2.
The magnetic properties of the cages are interesting, with 3 and $\mathbf{5}$ appearing to show slow relaxation of the magnetisation. Combined with previous results ${ }^{1,5-8}$ there are now seven examples of cobalt cages where a frequency dependent rise or maximum 
Table 3 Arrhenius parameters for slow relaxing Co(II) complexes

\begin{tabular}{|c|c|c|c|c|}
\hline Formula & $U_{\text {eff }}^{a} / \mathrm{K}$ & $A^{a} / \mathrm{s}$ & Ratio $\chi^{\prime}: \chi^{\prime \prime}$ & Ref. \\
\hline$\left(\mathrm{NMe}_{4}\right)_{3} \mathrm{Na}\left[\left\{\mathrm{Co}_{6}(\mathrm{cit})_{4}\left(\mathrm{H}_{2} \mathrm{O}\right)_{10}\right] \cdot 7 \mathrm{H}_{2} \mathrm{O}^{b}\right.$ & 26 & $8.2 \times 10^{-9}$ & $20: 1$ & 5 \\
\hline$\left(\mathrm{NMe}_{4}\right)_{4}\left[\left\{\mathrm{Co}_{6}(\mathrm{cit})_{4}\left(\mathrm{H}_{2} \mathrm{O}\right)_{10}\right] \cdot 6 \mathrm{H}_{2} \mathrm{O}^{c}\right.$ & 32 & $2.1 \times 10^{-9}$ & $20: 1$ & 5 \\
\hline$\left[\mathrm{Et}_{3} \mathrm{NH}\right]\left[\mathrm{Co}_{8}(\mathrm{chp})_{10}\left(\mathrm{O}_{3} \mathrm{PPh}\right)_{2}\left(\mathrm{NO}_{3}\right)_{3}(\mathrm{Hchp})_{2}\right]$ & $84( \pm 2)$ & $1.8( \pm 3) \times 10^{-12}$ or $2.1 \times 10^{-11}$ & $10: 1$ & 1 \\
\hline$\left[\mathrm{Co}_{12}(\mathrm{bm})_{12}\left(\mathrm{NO}_{3}\right)\left(\mathrm{O}_{2} \mathrm{CMe}\right)_{6}(\mathrm{EtOH})_{6}\right]\left(\mathrm{NO}_{3}\right)_{5}^{f}$ & 15.0 & $1.94 \times 10^{-7}$ & $3: 1$ & 7 \\
\hline$\left[\mathrm{Co}_{4}{ }_{4} \mathrm{Co}^{\mathrm{III}}{ }_{3}(\mathrm{HL})_{6}\left(\mathrm{NO}_{3}\right)_{3}\left(\mathrm{H}_{2} \mathrm{O}\right)_{3}\right]\left[\mathrm{NO}_{3}\right]_{2}{ }^{g}$ & $\mathrm{Nr}^{e}$ & $\mathrm{Nr}^{e}$ & $5: 2$ & 8 \\
\hline
\end{tabular}

${ }^{a}$ Derived from an Arrhenius treatment of the frequency dependence of the higher temperature peak in the $\chi^{\prime \prime} .{ }^{b}$ Partially desolvated sample, cit $=$ citrate. ${ }^{c}$ No crystallographic information reported; formula based on elemental analysis and IR data. ${ }^{d} \mathrm{hmp}=2$-hydroxymethylpyridine. ${ }^{e} \mathrm{Nr}=$ not reported. ${ }^{f} \mathrm{Hbm}=\left(1 \mathrm{H}\right.$-benzimidazol-2-yl)methanol. ${ }^{g} \mathrm{H}_{3} \mathrm{~L}=$ 2-amino-2-(hydroxylmethyl)-propane-1,3-diol.

in $\chi^{\prime \prime}$ has been seen at low temperature. Some data concerning the previous examples are given in Table 3 . In several of these compounds ratio of $\chi^{\prime \prime}$ to $\chi^{\prime}$ is low, which suggests that only a fraction of the cobalt cages are showing slow relaxation in any sample. However, the data reported for dodecanuclear and heptanuclear cages reported in 2007 by Zeng et al. ${ }^{7}$ and Ferguson et al., ${ }^{8}$ respectively, look more typical of SMMs. Both of these cages crystallise about a crystallographic three-fold axis, and whether symmetry is playing a role in influencing magnetic properties is debatable. Further work is required in an attempt to build up a database of experimental results in order to try to better understand the magnetic properties observed for $\mathrm{Co}$ (II) cages.

\section{Acknowledgements}

We thank the EPSRC (UK) for funding for a studentship (SL). We are also grateful to the EC-TMR "QueMolNa" and the EC-NE "MAGMANet" for support.

\section{References}

1 S. J. Langley, M. Helliwell, R. Sessoli, S. J. Teat, W. Wernsdorfer and R. E. P. Winpenny, Inorg. Chem., 2008, 47, 497-507.

2 M. I. Khan and J. Zubieta, Prog. Inorg. Chem., 1995, 43, 1-149, and references therein.

3 V. Chandrasekhar and S. Kingsley, Angew. Chem., Int. Ed., 2000, 39, $2320-2322$.

4 (a) R. Sessoli, H.-L. Tsai, A. R. Schake, S. Wang, J. B. Vincent, K. Folting, D. Gatteschi, G. Christou and D. N. Hendrickson, J. Am. Chem. Soc., 1993, 115, 1804-1816; (b) R. Sessoli, D. Gatteschi, A. Caneschi and M. A. Novak, Nature, 1993, 365, 141-3; (c) G. Aromi and E. K. Brechin, Struct. Bonding, 2006, 122, 1-68, and ref. therein; (d) D. Gatteschi and R. Sessoli, Angew. Chem., Int. Ed., 2003, 42, 268297, and ref. therein.
5 E.-C. Yang, D. N. Hendrickson, W. Wernsdorfer, M. Nakano, L. N. Zakharov, R. D. Sommer, A. L. Rheingold, M. Ledezma-Gairaud and G. Christou, J. Appl. Phys., 2002, 91, 7382-7384.

6 M. Murrie, S. J. Teat, H. Stöeckli-Evans and H. U. Güdel, Angew. Chem., Int. Ed., 2003, 42, 4653-4656.

7 M. H. Zeng, M.-X. Yao, H. Liang, W.-X. Zhang and X.-M. Chen, Angew. Chem., Int. Ed., 2007, 46, 1832-1835.

8 A. Ferguson, A. Parkin, J. L. Sanchez-Benitez, K. Kamenev, W. Wernsdorfer and M. Murrie, Chem. Commun., 2007, 3473-3475.

9 (a) J. F. Berry, F. A. Cotton, C. Y. Liu, T. Lu, C. A. Murillo, B. S. Tsukerblat, D. Villagrán and X. Wang, J. Am. Chem. Soc., 2005, 127, 4895-4902; (b) L. F. Chibotaru, L. Ungur, C. Aronica, H. Elmoll, G. Pilet and D. Luneau, J. Am. Chem. Soc., 2008, 130, 12445-12455; (c) S. Petit, G. Pilet, D. Luneau, L. F. Chibotaru and L. Ungur, Dalton Trans., 2007, 4582-4588.

10 R. E. P. Winpenny, J. Chem. Soc., Dalton Trans., 2002, 1-10.

11 J. Cosier and A. M. Glazer, J. Appl. Crystallogr., 1986, 19, 105-107.

12 SHELX-PC Package, Bruker Analytical X-ray Systems, Madison, WI, 1998.

13 S. Midollini, A. Orlandini, P. Rosa and L. Sorace, Inorg. Chem., 2005, 44, 2060-2066.

14 Harris notation describes the binding mode as $\left[\mathrm{XY}_{1} \mathrm{Y}_{2} \mathrm{Y}_{3} \cdots \mathrm{Y}_{\mathrm{n}}\right]$, where $\mathrm{X}$ is the overall number of metals bound by the whole ligand, and each value of $Y$ refers to the number of metal atoms attached to the different donor atoms. See: R. A. Coxall, S. G. Harris, D. K. Henderson, S. Parsons, P. A. Tasker and R. E. P. Winpenny, J. Chem. Soc., Dalton Trans., 2000, 2349-2356.

15 A. Müller, P. Kögerler and H. Bögge, Struct. Bonding, 2000, 96, $203-$ 236.

16 F. J. Rietmeijer, G. A. van Albada, R. A. G. de Graaff, J. G. Haasnoot and J. Reedijk, Inorg. Chem., 1985, 24, 3597-3601.

17 A. Bell, G. Aromí, S. J. Teat, W. Wernsdorfer and R. E. P. Winpenny, Chem. Commun., 2005, 2808-2810.

18 (a) E. K. Brechin, A. Graham, A. Parkin, S. Parsons, A. M. Seddon and R. E. P. Winpenny, J. Chem. Soc., Dalton Trans., 2000, 3242-3252; (b) G. Aromi, A. S. Batsanov, P. Christian, M. Helliwell, A. Parkin, S. Parsons, A. A. Smith, G. A. Timco and R. E. P. Winpenny, Chem.Eur. J., 2003, 9, 5142-5161; (c) T. O. Denisova, M. A. Golubnichaya and S. E. Nefedov, Russ. Chem. Bull., 2003, 52, 2760-2763; (d) R. W. Saalfrank, I. Bernt and F. Hampel, Chem.-Eur. J., 2001, 7, 2770-2774; (e) E. K. Brechin, S. G. Harris, A. Harrison, S. Parsons, G. A. Whittaker and R. E. P. Winpenny, Chem. Commun., 1997, 653-654. 